\title{
BRASILEIROS MIGRANTES NA LITERATURA
}

\author{
Teresa Sales*
}

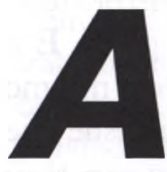

academia se debruça sobre o fenômeno das migrações analisando seus aspectos demográficos, econômicos, sociais e políticos. Há porém uma outra perspectiva pela qual têm sido abordadas as migrações, sejam elas internas a um país ou internacionais. Pelo seu caráter de epopéia, de êxodo e de aventura que mobiliza milhares de pessoas em movimentos de desenrasizamento, as migrações têm dado origem a uma vasta produção literária. É nessa produção literária que melhor se expressa o drama humano das migrações. Quem melhor do que Steinbeck para expressar o êxodo rural provocado pela Crise de 1929 nos Estados Unidos?

Apesar da recência de nossa emigração em direção a outros países, a partir do momento em que me interessei por esse fenômeno, fiquei atenta à produção literária sobre $\mathrm{o}$ assunto ${ }^{1}$. $\mathrm{O}$ que encontrei foi ainda muito pouco. Porém já com algumas obras sugestivas e que indicam um campo fértil para outros trabalhos, à medida em que o Brasil solidifica sua posição de país também de emigração. Sobre a imigração de outros povos para nosso país a produção artística e literária é não apenas abundante, como muito presente na mídia de grande audiência, tal como nas novelas da Rede Globo que espalham a imagem do Brasil mundo afora. Houve apenas uma novela dessa emissora de televisão onde o tema do imigrante brasileiro nos Estados Unidos foi levantado, porém logo esmaecido por outros aspectos secundários da trama que vieram a tomar o primeiro plano.

Na primeira parte desse artigo analiso alguns trabalhos pioneiros que utilizaram uma abordagem jornalísticodescritiva da emigração dos brasileiros e de seu cotidiano imigrante em países estrangeiros. Na segunda parte analiso obras de ficção propriamente. Em ambas as partes sigo a ordem cronológica da publicação das obras ${ }^{2}$. Concluo o artigo com algumas considerações sobre aspectos sociológicos que emergem dessas obras literárias.

\section{NARRATIVAS DAS MIGRAÇÕES}

Um dos primeiros livros sobre o imigrante brasileiro em outros países foi o do psiquiatra valadarense José Victor Bicalho (1989) intitulado: Yes, eu sou brazuca. Para escrever sua narrativa, o autor viveu ele próprio a experiência de morar e trabalhar com os brasileiros na região da Grande Boston, no Estado de Massachusetts, nos Estados Unidos. A narrativa se passa basicamente no entorno de Framingham, um dos municípios daquela região. As estórias dos personagens se entrelaçam, qual um romance de ficção, até se encontrarem algumas num retorno ao Brasil. $\mathrm{Na}$ narrativa são exploradas as situações de relações afetivas e sexuais entre os personagens, a comunicação com o Brasil, a saudade, e sobretudo o cotidiano de trabalho e de moradia nos Estados Unidos. Não faltou também uma viagem pelo México, com todo o conteúdo de aventura que ela necessariamente implica, bem como o drama da moça originária de uma pequena cidade brasileira e que nos Estados Unidos passou a trabalhar de gogo girl. Apesar de retratar com mais ênfase as situações atribuladas do imigrante brasileiro, onde o frio e a saudade são uma constante, aparecem também os momentos agradáveis da vivência brasileira do futebol, da cerveja e do churrasco compartilhados pelos amigos.

Escrito com uma linguagem pouco elaborada e sem uma definição clara entre o trabalho acadêmico e a ficção, o livro de Bicalho tem seu valor por ser o primeiro a abordar e documentar a imigração dos brasileiros nos Estados Unidos. Tanto que Maxine Margolis (1994) utizou vários dados apresentados por Bicalho para comparar com os seus colhidos em Nova York. Além dessa incipiente documentação, o livro de Bicalho apontou uma situação que tenderia a se intensificar nos anos subsequentes à sua pesquisa, quando afirmou que o verdadeiro brazuca é aquele que não mais conseguiria viver no Brasil, aquele que ficaria em um vaivém sem fim. Margolis chamaria a esse movimento de migração ioiô.

Sobre a migração Brasil-Paraguai, um dos trabalhos mais instigantes que li quando realizei uma pesquisa sobre migração entre os países do Mercosul no ano de 1994 foi o da jornalista Cácia Cortêz, Os Brasiguaios (1993). Além de 
fornecer um panorama desse movimento migratório desde suas origens, a jornalista descreve em cores vivas o movimento de retorno dos brasiguaios para os primeiros acampamentos em regiões de fronteira entre o Brasil e o Paraguai.

Mais do que a emigração do Brasil para o Paraguai, o aspecto mais interessante da descrição de Cácia Cortêz se refere a esse movimento de retorno desses migrantes brasileiros, que ficaram conhecidos como brasiguaios sobretudo nesse retorno. Eles migram de volta ao Brasil aos primeiros sinais de um plano de reforma agrária proposto pelo então governo da Nova República que se instaura no nosso país após as eleições indiretas que, com a morte de Tancredo Neves, leva ao poder o presidente José Sarney. Vem daí as primeiras experiências de acampamentos, que ocorrem justamente em regiões de fronteira entre o Brasil e o Paraguai.

Ainda sobre a região da Grande Boston nos Estados Unidos, existe uma outra narrativa mais atual do que aquela de José Victor Bicalho referida anteriormente. Produzido parcialmente com recursos da própria autora - Heloísa Souza, jornalista que mora e trabalha em Boston, na Secretaria de Educação, além de estar à frente do Grupo Mulher Brasileira - esse trabalho foi divulgado em 1997 e se chama Retrato em Branco e Preto - narrativa de mulheres brasileiras imigrantes na área da Grande Boston - 1995-1996. Trata-se da transcrição ipsis literis de 11 entrevistas realizadas com mulheres brasileiras, narrando suas experiências de gênero, trabalho, família, Brasil versus Estados Unidos. Como a maioria das mulheres entrevistadas ( 8 dentre as 11 , ou seja, cerca de 3/4) pertencem a movimentos de apoio à comunidade brasileira na região da Grande Boston, sendo também a maior parte delas (também cerca de 3/ 4) constituída de pessoas com nível superior de escolaridade, o resultado é de um perfil bastante diferenciado das mulheres. $\mathrm{O}$ que não tira o mérito do trabalho, pois embora a diferenciação positiva em nível educacional tenha vindo na bagagem das entrevistadas, a sua identidade de gênero e sobretudo a sua identidade étnica enquanto grupo imigrante, foram construídas em grande medida na sua vivência enquanto mulheres imigrantes.

Outra narrativa de mulheres migrantes na região de Boston está contida em meu livro Brasileiros Longe de Casa, (Sales, 1999). Copio de mim mesma uma fórmula que deu certo em "Agreste, Agrestes" (Sales, 1982), e pelo mesmo motivo: uma certa insatisfação em não ver incorporadas ao texto final tantas estórias boas que me foram contadas na pesquisa e que ficaram sem lugar no transcorrer dos capítulos do livro. Elas se intercalam entre os capítulos como se fossem fotografias ou desenhos para ilustrar as interpretações. São ao todo sete narrativas de mulheres (por mim recriadas livremente e usando, como para todas as demais citações de entrevistas, nomes fictícios), contadas em três episódios - Aventura, Trabalho, Dilema.

\section{OBRAS DE FICÇÃO SOBRE AS MIGRAÇÕES}

Os cinco livros publicados e divulgados em grande circuito por editoras comerciais, são todos eles trabalhos de ficção que, a meu juízo, foram melhorando de qualidade dos primeiro até os últimos. O primeiro que chegou às livrarias foi 46th Street - o caminho americano, de autoria de Luiz Alberto Scotto e publicado pela Brasiliense em 1993. A leitura desse livro provocou em mim uma reação semelhante a de uma de minhas entrevistadas na pesquisa que realizei em Framingham (município da região metropolitana de Boston, Estados Unidos) em 1996, em face de sua leitura do livro de Victor Bicalho: "mas ele só viu o lado ruim?"

O livro é uma sucessão de droga, sexo, crime, homicídio, suicídio e além disso com um final de extremo mau gosto. É um livro que expressa contudo, com muita clareza, o estereótipo do malandro brasileiro. Cito dois exemplos: um em que o personagem comunica sua decisão de deixar Nova York e uma das razões é que "está vindo muito brasileiro pra cá. Isso aqui está virando um troço pavoroso. Não é pelos brasileiros. É pela falta de experiência nossa em viver no exterior. A gente quer viver fora como se estivesse no Brasil. Aí vamos nos comer, nos devorar: sacanagem pra todo lado, durante todo tempo" (p.68). E o outro ao final do livro, quando o mesmo personagem diz: "gostei dele desde que apareceu na agência. Aquele tipo esperto, malandrinho mesmo. Made in Brazil, manja?" (p.156).

Esse estereótipo é também um tema recorrente no livro publicado três anos depois, que aliás foi um ano profícuo em livros de ficção sobre o imigrante brasileiro. Trata-se do livro de Roberto Athayde, Brasileiros em Manhattan, publicado pela Topbooks em 1996. Nesse livro o autor, com mais domínio da trama e da linguagem (autor já conhecido, tendo antes publicado a conhecida peça de teatro "Apareceu a Margarida"), apresenta a todo tempo situações de esperteza e malandragem do brasileiro. São porém histórias mais divertidas, frequentemente contrastadas com a cultura americana através dos personagens daquele país que entram em cena convivendo com os brasileiros. $\mathrm{O}$ mundo dos brasileiros nesse livro ainda é o submundo de Nova York, onde esporadicamente aparecem as situações de trabalho, mas como se fossem cenas que ficam para trás, sem aparecer no palco.

Esse livro de Roberto Athayde encerra-se com considerações do autor sobre a recente migração de brasileiros para países do Primeiro Mundo: "Nova York, seja pelas vastas perspectivas que oferecia à juventude oriunda do Brasil, seja pela importância de suas boates ou pela intensa vida cultural que lhe 
proporcionava, parecia a Vladimir um ideal que merece ser difundido e promovido junto a todo o povo brasileiro, sem discriminação [...] É mister cooptar os segmentos menos visíveis da nossa sociedade, se quisermos penetrar no terceiro milênio com um Brasil firmemente emparelhado ao Primeiro Mundo através desses heróicos incorformados, dispostos a empurrar nossas fronteiras ao hemisfério norte" (p.282).

O outro livro de ficção sobre o tema "brasileiro imigrante em países do Primeiro Mundo" da leva de 1996, é de uma escritora, contista, também ela já com experiência literária. Trata-se do livro Pau-de-Arara Classe Turística, de Regina Rheda, publicado pela Editora Record. Esse livro tem claramente a marca de gênero (é basicamente a experiência de uma imigrante mulher) encravada na obra de ficção. Fazendo um percurso migratório através de sua personagem que parte do Brasil e vive suas experiências de vida e de trabalho em Londres e na Itália, a autora relata com extrema sensibilidade situações de liminaridade que poderiam ser vividas por qualquer migrante brasileira em semelhante situação.

Aqui a autora, à semelhança do autor de Brasileiros em Manhattan, introduz considerações de natureza sociológica em sua obra de ficção, com a diferença que ela o faz já ao início do livro, e não ao seu final. Assim ela o inicia: "Nas décadas finais do século $\mathrm{XX}$, o Brasil viveu um fenômeno inédito em seus quinhentos anos de história. Um grande número de jovens brasileiros de classe média decidiu trocar o diploma pelo esfregão, a roupa de grife pelo avental, o volante pela pia, a prosperidade pela gorjeta e o Brasil pelo Primeiro Mundo [...] A informação de que descendentes de estrangeiros tinham direito ao passaporte do país dos ancestrais espalhou-se entre a juventude com a velocidade de um mexerico" (p. 7). Essa é a base da crônica de viagem de sua personagem, onde o contraste do brasileiro com outra cultura fica muito evidente, porém aqui sem o peso tão forte do estereótipo brasileiro malandro. Mas sim um olhar algo irônico de uma jovem brasileira que faz naquele país serviços destinados hoje em dia aos imigrantes (no caso da personagem, sobretudo os serviços domésticos) e que vê por dentro a hipocrisia da falsa moral assentada em valores religiosos arraigados.

Ainda da leva de 1996, o livro Clandestinos - Aventuras verídicas de um guia de imigrantes ilegais nas Fronteiras Americanas é atípico em relação aos três anteriores, por não ser uma obra de ficção propriamente, muito embora, tal como o de Victor Bicalho, aqui também o autor faça sua narrativa em forma de ficção. O próprio título do livro já é suficiente para definir o que ele contém. $\mathrm{O}$ autor é desconhecido e usa o pseudônimo de Thales de Leon. Usa-o de propósito para não ser identificado, exatamente pelo conteúdo das estórias que vão relatadas no livro, algumas com implicações que poderiam prejudicá-lo.

As situações de risco vividas por um homem comum que se torna atravessador de migrantes brasileiros clandestinos na fronteira MéxicoEstados Unidos, mostram um retrato muito próximo a uma realidade frequentemente referenciada nos exemplos e nas representações dos brasileiros imigrantes de minha amostra de pesquisa, como algumas peças de teatro a que lá assisti, escritas e encenadas por pessoas da comunidade católica na Paróquia de São Tarcísio em Framingham.

E finalmente, o último livro de ficção que saiu publicado sobre esse assunto (pela Rocco Editora em 1997), Estrangeiros do trem $N$, tem também como cenário Nova York. Aqui os protagonistas da história fazem uma conexão mais elaborada entre as experiências de trabalho e de vida no Brasil e nos Estados Unidos. Embora seja uma obra de pura ficção, do melhor estilo, o autor - Sérgio Vilas Boas, jornalista e escritor - baseou seu livro numa composição de informações extraídas em mais de 100 entrevistas feitas com imigrantes brasileiros em Nova York de setembro de 1993 a outubro de 1994, além do material de dados secundários.

Paralelo à trama principal do livro, o autor usa as situações de entrevistas para apresentar vários personagens secundários (e o gênero aqui é tipicamente masculino, ao contrário do livro de Regina Rheda referido acima), através dos quais tece considerações preciosas sobre a vida de trabalho do brasileiro imigrante em Nova York, bem como de seus parâmetros comparativos da cultura brasileira versus a cultura americana. Tendo o livro de Maxine Margolis (1994) como um parâmetro invisível para sua narrativa, Vilas Boas encerra o seu livro constatando a típica situação do cidadão ioiô vivenciada por um de seus personagens, onde se passa a convivência de duas metades - uma brasileira e outra americana. E encerrao também constatando que "ninguém é o mesmo depois de romper fronteiras" (pag. 382).

\section{CONSIDERAÇÕES FINAIS}

Esse "ninguém é o mesmo" faz parte na verdade de um processo social vivido em várias etapas de romper fronteiras. E esse processo implica em levas (sucessivas no tempo) de migrantes que vão, que retornam ao Brasil, que voltam novamente ao país de destino, formando assim uma cadeia que aos poucos vai se solidificando, assentada nas várias redes sociais que nada mais são do que os sustentáculos para a continuidade daquela cadeia migratória, resultando na formação de um novo grupo étnico.

Essas redes sociais são então a base de sustentação da nova etnia que começa a se constituir, a partir sobretudo do momento em que a perspectiva é de uma permanência mais longa (para não falar ainda em definitiva) no país de destino. 
A partir do momento em que o brasileiro imigrante em outros países começa a se constituir enquanto um grupo étnico, ele vai construindo sua própria auto-imagem enquanto grupo, em sua alteridade com os demais grupos étnicos da sociedade de destino. Essa auto-imagem é veiculada não apenas através do olhar do entrevistador, que a reproduz em suas análises (refiro-me aqui especificamente a meu livro Brasileiros Longe de Casa, Sales, 1999), mas também através dos meios de comunicação, tanto na imprensa, como, no caso aqui analisado, nas obras literárias.

No caso da imprensa ${ }^{3}$, vale a pena ressaltar aqui apenas o contraste entre o enfoque da imprensa brasileira e o da imprensa americana.

Quando comecei a acompanhar as notícias da imprensa sobre os novos fluxos migratórios da população brasileira, a partir do banco de dados mantido pelos alunos bolsistas da pesquisa desde o primeiro projeto $\mathrm{CNPq}$ em 1993, um dos aspectos que logo me chamou a atenção foi o conteúdo das notícias que saíam na imprensa americana, em comparação com o que era veiculado na imprensa brasileira. Se do lado da imprensa brasileira " $2 / 3$ dos temas abordados na imprensa, nessa amostra de matérias a que tivemos acesso num primeiro levantamento, têm uma sinalização visivelmente negativa quanto ao teor desses novos fluxos migratórios do Brasil" (referia-me aos temas sobre clandestinidade, criminalidade e discriminação) (Sales, 1994:108), do lado da imprensa americana a sinalização era muito mais positiva.

Nas 15 matérias divulgadas pelo Boston Globe entre 1993 e 1997 sobre imigrantes brasileiros (sem contar outros jornais onde os imigrantes brasileiros só apareceram esporadicamente), dois aspectos que foram recorrentes em várias notícias eram relacionados à valorização do imigrante brasileiro pelo seu trabalho, e ao fato de sua ascensão social através dos negócios (ou comércio étnico) mantidos pelos brasileiros na Grande Boston, sobretudo nas cidades de Framingham, Marlborough e Somerville.

A valorização do imigrante brasileiro pelo seu trabalho também é um aspecto recorrente nos livros analisados anteriormente. Pude observar que há uma certa sequência temporal nessa valorização do imigrante pelo seu trabalho. Pois os primeiros livros de ficção sobre o brasileiro imigrante ressaltam muito mais o estereótipo do brasileiro malandro. Essa é a marca principal, por exemplo, do livro de Scotto (1993). No livro de Athayde, publicado três anos depois (1996), também há uma exploração muito grande desse estereótipo do brasileiro malandro no submundo de Nova York. Mas já aparecem aí mais situações que mostram o brasileiro trabalhador, situações cada vez mais recorrentes nos demais livros de ficção apresentados na segunda seção desse artigo.

Na primeira seção do artigo, quando analiso as narrativas relativas ao imigrante brasileiro na região de Boston (não estou considerando aqui a narrativa sobre os Brasilguaios, que tem sua especificidade por ser um contexto de migração de fronteiras e de trabalhadores rurais), é sobretudo o mundo do trabalho que está presente, o que é sem dúvida condizente com o que se sabe sobre a migração de brasileiros para essa região dos Estados Unidos, caracterizada sobretudo por ser uma migração de mão-de-obra (ou migração laboral, como se diria com mais precisão linguística em espanhol). Na sequência das narrativas de Bicalho (1989), Souza (1997) e Sales (1999), há também uma ênfase no imigrante brasileiro pela sua vinculação ao mundo do trabalho, sendo esse inclusive o título de um dos episódios em que se dividem as sete histórias de Sales.

\footnotetext{
* Teresa Sales é Pesquisadora do Núcleo de Estudos de População - NEPO/ Unicamp.
}

\section{NOTAS}

1 - Esse artigo é parcialmente retirado de meu livro SALES, 1999.

2 - Adianto que a minha pesquisa não foi exaustiva e que, portanto, possivelmente existirão outras obras que não conheço e sobre as quais gostaria de tomar conhecimento, caso os prezados leitores de Travessia puderem se comunicar com os editores da revista com indicaçōes a respeito.

3 - Analiso mais detidamente esse assunto em Sales, 1999.

\section{REFERÊNCIAS BIBLIOGRÁFICAS}

ATHAYDE, Roberto

(1996) Brasileiros em Manhattan. Rio de Janeiro, Topbooks.

BICALHO, José Victor

(1989). Yes, eu sou brazuca. Governador Valadares, Gráfica Ibituruna.

CORTÊZ, Cácia

(1993) Brasiguaios: Os refugiados desconhecidos. São Paulo, Brasil Agora.

LEON, Thales de

(1996) Clandestinos - Aventuras verídicas de um guia de imigrantes ilegais nas fronteiras americanas. Rio de Janeiro, Domínio Público.

MARGOLIS, Maxine

(1994) Litle Brazil: Imigrantes brasileiros em Nova York. Campinas, Papirus.

RHEDA, Regina

(1996) Pau-de-arara classe turística. Rio de Janeiro, Record.

SALES, Teresa

(1982) Agreste, Agrestes: Transformações recentes na Agricultura Nordestina. Rio de Janeiro, Paz e Terra; São Paulo, Editora Brasileira de Ciências.

SALES, Teresa

(1994) "Brasil Migrante, Brasil Clandestino". São Paulo em Perspectiva. vol.8, ne1, jan/mar.

SALES, Teresa

(1999) Brasileiros Longe de Casa. São Paulo, Cortez Editora.

SCOTTO, Luiz Alberto

(1993) 46th Street - O caminho americano. São Paulo, Brasiliense.

SOUZA, Heloísa

(1997) Retrato em Branco e Preto - narrativa de mulheres brasileiras imigrantes na Área da Grande Boston - 19951996.

VILAS BOAS, Sérgio

(1997) Os Estrangeiros do trem N. Rio de Janeiro, Rocco. 